\title{
DISEÑO DE UNA POLÍTICA PÚBLICA REGIONAL DE ACREDITACIÓN DE LA EDUCACIÓN SUPERIOR EN CENTROAMÉRICA (1993-2003). MARIANELA AGUILAR ARCE. SAN JOSÉ: EDITORIAL UCR, 2018
}

Allan Abarca Rodríguez

\author{
Recibido: 26/02/2019 - Aceptado: 18/03/2019
}

La educación superior se ha constituido en un desafío permanente para las sociedades. En la teoría de las políticas públicas, se diría que permanece en la agenda pública y que su inclusión se debe a múltiples factores, de manera que es innegable la existencia de un interés público en su regulación. Las dimensiones que alcanza una política pública pueden ser institucionales, regionales, nacionales o internacionales. Estas últimas -las internacionales- nacen en una complejidad de voluntades que se comunican y se coordinan entre sí y que requieren elementos especiales desencadenantes que culminen con la cristalización de una política determinada.

La obra que nos presenta Marianela Aguilar Arce sistematiza el proceso de formulación de una política pública que concreta una instancia de acreditación en Centroamérica, en materia de educación superior. En el discurrir del relato se descubren situaciones y contextos que le permiten al lector descubrir el ADN político y tecnocrático con el cual se gesta una política pública de esta naturaleza.

A los estudiosos de las políticas públicas, en general, y de las de educación superior, en particular, el libro es más que un recuento de episodios claves que estimulan la aparición de la política regional supracitada. Las explicaciones sobre los escenarios en los cuales se discute el diseño de la política se complementan con interpretaciones que dan cuenta de lo que se denomina "la hechura de las políticas públicas", esto es, una lógica constitutiva de esta.

La autora se auxilia en documentos institucionales y en una serie de entrevistas, los cuales sirven para llevar a cabo una reconstrucción del desarrollo histórico de esta política regional de acreditación. El acceso a fuentes primarias privilegiadas hace que la sistematización e interpretación del proceso político genere una obra inédita en el tema.

Además, el libro se convierte en una herramienta valiosa para aquellas personas que deban tomar decisiones en otras regiones planetarias, en virtud de la singularidad de la política pública desarrollada. Esto es, la hace susceptible de una transferencia de políticas (policy transfer, en la terminología original anglosajona). 
Aunque aisladas entre sí, las preocupaciones tanto de cada Ministerio de Educación de los países de la región como del propio Consejo Superior Universitario Centroamericano (CSUCA) decantan en un proceso de foros que fueron la base de la formulación de la política. La toma de decisiones acerca de cómo abordar el aseguramiento de la calidad de la educación superior se da, entonces, mediante un proceso relativamente incremental y bajo la consigna de una red de políticas públicas.

En la teoría de las políticas públicas, normalmente las redes son recursos inevitables de temas que convocan actores de diversa naturaleza, muchos de estos de igual estatus, quienes solo mediante un mecanismo de consenso pueden articular la respuesta pública requerida. La autora explica con detalle los antecedentes de la política, la construcción de los acuerdos, los aspectos amenazantes, la confluencia de actores de la sociedad civil y los entretelones de la política. La cooperación internacional -en este caso la alemana- se constituyó en un elemento trascendente que le genera factibilidad a la propuesta, tanto para la fase de discusión-formulación, como la de constitución formal de la propuesta de política pública.

En el fondo se está en presencia de un esfuerzo integrador que depara una política pública regional. En términos de la taxonomía ideada por Lowi, se está en presencia de una política pública regulativa, puesto que refiere a mecanismos y estándares a instituir en una materia específica. Adicionalmente curioso es que la esencia de la educación superior es que su acceso es elemental como política pública redistributiva. En otras palabras, una política de calidad en educación superior guarda vínculo tanto con un plano regulativo como con una dimensión redistributiva.

Por eso hace bien la autora en anteceder su análisis de la política de acreditación regional a una discusión sobre el carácter de bien público o privado de la educación superior, ya que los esfuerzos acreditadores se erigen en medio de la discusión acerca de la automatización mercantil de la educación superior como servicio, como mecanismo de ascenso social, o de ambos. Como bien lo refiere la autora, la discusión en torno a una política pública de calidad en educación superior no está exenta de perspectivas ideológicas.

El aseguramiento de la calidad de la educación superior se ha constituido en una preocupación de los Estados. No se reduce al simple consumo de un bien normal más, la calidad con la cual es ofrecida tiene consecuencias inevitables en el desarrollo de una sociedad, mucho más hoy día en que la movilidad de técnicos y de profesionales entre los países tiene consecuencias de dimensiones múltiples e irreversibles.

La formación de Marianela Aguilar como relacionista internacional y politóloga le permite caracterizar los actores, los intereses, el contexto y las dimensiones habidas en la ruta de diseño de la política; si a eso sumamos su amplia experiencia en puestos de dirección institucional y de asesoría directa en materia propia de calidad de la educación superior, hace obligatoria la lectura del libro Diseño de una politica pública regional de acreditación de la educación superior en Centroamérica (1993-2003). 
Es imperdible para estudiosos de la formulación desde las políticas públicas, para interesados en los problemas y desafíos en lo regional, y para quienes la educación superior representa un reto permanente.

Allan Abarca Rodríguez. Costarricense. Profesor catedrático, se desempeña como docente-investigador en la Escuela de Salud Pública de la Facultad de Medicina y en la Escuela de Ciencias Políticas de la Facultad de Ciencias Sociales, ambas en la Universidad de Costa Rica. Es Licenciado en Ciencias de la Educación, Licenciado en Ciencias Políticas, Magíster en Políticas Públicas, Magíster en Salud Pública. Particularmente ha estudiado políticas públicas en el ámbito de la educación y de la salud.

Contacto: allan.abarca@ucr.ac.cr

ORCID: 0000-0002-5852-1744 
